\title{
An Automated Lab-Scale Flue Gas Permeation Membrane Testing System at the National Carbon Capture Center
}

\section{Victor A. Kusuma ${ }^{1,2,}$, Surendar R. Venna ${ }^{1,2}$, Shan Wickramanayake ${ }^{1,2}$, Ganpat J. Dahe'1, Christina R. Myers' ${ }^{1}$, John 0'Connor ${ }^{1,2}$, Kevin P. Resnik ${ }^{1,2}$, Justin H. Anthony3, David Hopkinson'}

1 U.S. Department of Energy, National Energy Technology Laboratory, 626 Cochrans Mill Rd, Pittsburgh, Pennsylvania 15236, USA

${ }^{2}$ AECOM Corporation, 626 Cochrans Mill Rd, Pittsburgh, Pennsylvania 15236, USA

${ }^{3}$ Southern Company Services, PO BOX 1069, Wilsonville, Alabama 35186, USA

Submitted to Journal of Membrane Science

* Corresponding author:

VAK: victor.kusuma@netl.doe.gov, +1 4123865859

Alt: DH: david.hopkinson@netl.doe.gov, +1 3042854360

(C) 2016. This manuscript version is made available under the Elsevier user license http://www.elsevier.com/open-access/userlicense/1.0/ 


\section{Abstract}

A constant pressure, mixed gas permeation testing skid was deployed at the National Carbon Capture Center to test membrane performance when continuously exposed to slipstream postcombustion flue gas. Small, laboratory scale membranes can be loaded for testing and the degree of automation allowed the skid to be run unattended for several weeks at a time. In this report, we share our experience in commissioning the skid and quantifying $\mathrm{CO}_{2}, \mathrm{~N}_{2}$ and $\mathrm{O}_{2}$ permeances of several membranes during the first round of testing. Dense films of polydimethylsiloxane and poly(bistrifluoroethoxyphosphazene) were tested with flue gas for approximately 20 hours each. In addition, we successfully tested four thin film composite hollow fiber membranes made by a dip coating process, consisting of porous Torlon hollow fibers coated with a selective layer of poly(bistrifluoroethoxyphosphazene) or its mixed matrix with a metal organic framework SIFSIX$\mathrm{Cu}-2 \mathrm{i}$ filler particles. Initial results suggest the polydimethylsiloxane showed comparable results to the literature data, but the coated hollow fiber membranes have lower $\mathrm{CO}_{2}$ permeances relative to $\mathrm{N}_{2}$ or $\mathrm{O}_{2}$ permeances compared to their performance under idealized, dry, contaminant-free mixed gas conditions. While quantification of $\mathrm{H}_{2} \mathrm{O}$ permeance was performed, we found it was affected by concentration polarization even with small membrane area and a low stage cut.

Keywords: membrane, constant pressure permeation, slipstream flue gas, $\mathrm{CO}_{2}$ capture, National Carbon Capture Center 


\section{Introduction}

The Carbon Capture R\&D program conducted by U.S. Department of Energy/National Energy Technology Laboratory (DOE/NETL) is aimed toward accelerating the development of costeffective $\mathrm{CO}_{2}$ emission mitigation technologies. An important part of this program is the DOE's National Carbon Capture Center (NCCC)'s Post Combustion Carbon Capture Center (PC4) facility, where a pulverized coal flue gas slipstream supplied by the E.C. Gaston steam plant operated by Alabama Power is made available for various technology partners to demonstrate their carbon capture technologies in field trials [1-3]. Most of these partners constructed purpose-built testing skids aimed toward testing their own technology, typically at advanced bench or small pilot scale. For instance, Membrane Technology Research (MTR) recently completed a two year, 1 ton/day post-combustion flue gas test with their Polaris ${ }^{\mathrm{TM}}$ membrane modules [1]. While the capability for testing membranes with real flue gas at NCCC-PC4 is attractive to many research programs in the US, the large scale and often specific or proprietary nature of these developer skids make it difficult for smaller research groups to test their most promising membranes without constructing their own testing skids, which takes significant time, expense and expertise. In 2014, when our team at NETL decided to construct a lab-scale membrane testing skid to be installed at the NCCC-PC4, we recognized that such a skid could be useful not only as part of our own membrane development effort [4], but also to provide a universal membrane testing platform at NCCC-PC4 that could help accelerate technology development for many other research groups.

This paper describes our successful effort to develop the NETL Post-Combustion Membrane Testing Skid (PCMS), the experimental challenges and considerations, and the promising initial results from our membranes. Despite the short-term and unoptimized nature of these demonstration tests, the PCMS was ultimately designed for long term minimally attended operation. Seven membranes, in both flat sheet film and hollow fiber formats, were successfully tested over short periods using flue gas supplied by NCCC. For all these membranes, $\mathrm{CO}_{2}, \mathrm{O}_{2}, \mathrm{~N}_{2}$ and water vapor permeance were quantified over a period between 15 to 22.5 hours. The results generally agreed well with literature data or experiments performed using other permeation instruments at NETL but did hint of potential performance reduction even in pre-conditioned flue gas. This report of the experience gathered in constructing the PCMS will help the broader research community interested in undertaking a similar effort using real or simulated flue gas to accelerate carbon capture technology development. 


\section{Theory}

The PCMS is a constant pressure (isobaric) mixed gas permeation system with a basic design that has been widely used and reported by many membrane research groups, including ours [5-9], emphasizing experiment automation to allow unattended operations for an extended period. Briefly, a membrane is sealed in a specialized pressure cell which isolates the feed (upstream) from the permeate (downstream) side, allowing gas exchange between the two sides to happen only by diffusion through the membrane. For a mixed-gas permeation measurement, it is important to minimize gas composition change over time on both sides that result from diffusion through the membrane. This is achieved by constantly flowing the feed gas at a particular flowrate and pressure on the upstream side to sweep the entire membrane face, and to do the same on the downstream side using a sweep gas. The experiment is typically set up such that the feed flow is much greater than the amount of gas permeating through the membrane to minimize compositional changes on both feed and sweep streams: the stage cut (i.e. ratio of transmembrane gas flow to the feed flowrate) is typically less than $1 \%$ [10]. The permeances of the individual components can be calculated by measuring the permeate stream (i.e. the stream consisting of sweep gas plus permeating components) flowrate and its composition. In the PCMS, because the major flue gas components are present cumulatively less than $1 \%$ in the permeate stream, we used a gas chromatograph (GC) to perform the analysis: therefore, the sweep gas chosen is the same as the GC carrier gas.

The permeance of a particular gas component A through the membrane is defined as the gas flux normalized by the partial pressure differential between the upstream or downstream side, or mathematically [11]:

$$
\mathrm{Q}_{A}=\frac{N_{A}}{p_{2, A}-p_{1, A}}
$$

where $Q_{\mathrm{A}}$ is the permeance of component A (in this study, expressed in terms of gas permeation unit, or GPU, $\left.10^{-6} \mathrm{~cm}^{3}(\mathrm{STP}) / \mathrm{cm}^{2} . \mathrm{s} . \mathrm{cmHg}\right), N_{A}$ is the transmembrane gas flux, $p_{2, A}$ and $p_{1, A}$ are the upstream and downstream partial pressures of A, respectively. In this measuring scheme, the gas flux is defined in terms of the permeate flowrate and gas composition by:

$$
N_{A}=\left(\frac{\dot{v}_{1}}{A}\right) x_{1, A}
$$

where $\dot{v}_{1}$ is the permeate stream flowrate, $A$ is the membrane area and $x_{1, A}$ is the mole fraction of component $\mathrm{A}$ in the permeate stream. Combining equations 1 and 2 , therefore, yields: 


$$
Q_{A}=\frac{\dot{v}_{1} x_{1, A}}{A\left(P_{2} x_{2, A}-P_{1} x_{1, A}\right)}
$$

where $P_{2}$ and $P_{1}$ denote feed and permeate stream pressures, respectively, and $x_{2, A}$ is the mole fraction of component $\mathrm{A}$ in the feed stream. Whenever the selective layer thickness is known definitively, i.e. in the case of homogeneous thin film membranes, gas permeability (here given in the customary unit Barrer, $10^{-10} \mathrm{~cm}^{3}(\mathrm{STP}) . \mathrm{cm} / \mathrm{cm}^{2} . \mathrm{s} . \mathrm{cmHg}$ ) can be calculated by multiplying the individual permeance $Q$ with the membrane thickness.

Equation 3 has an inherent assumption that the gas compositions on either side of the membrane are near constant throughout, i.e. the partial pressures of gaseous components of the feed stream are not significantly changed in the retentate, the partial pressures of permeated gases are very low in the permeate stream, and pressure drop along the length of the hollow fiber membranes is negligible. By keeping the experiment at low stage cut $(<1 \%)$, this condition was met for most components in the PCMS. However, it is worth paying special attention to water vapor, which typically has very high permeance through a membrane and is present at low concentrations in the feed stream. Thus, even a relatively small membrane area is sufficient to deplete water vapor content between the feed stream and the retentate stream significantly. In the case of hollow fiber membranes, water vapor concentration could also vary significantly along the membrane length $[12,13]$. Since we performed our hollow fiber experiments in a counter-current flow configuration with approximately equal pressure and flowrates between the upstream and downstream sides (cf. Table 1 in a latter section), the compositional change on the two sides were approximately balanced. Therefore, we still can use Equation 3 to calculate the water vapor permeance in the hollow fiber membranes as a first approximation. Later we will show that the concentration polarization effect was significant enough anyway to prevent determination of the true water vapor permeance for these membranes.

\section{Equipment Design}

\subsection{Flow design}

The PCMS was designed to test membranes using treated post-combustion flue gas from a pulverized coal combustion plant as the only expected feed stream. The flue gas from the Unit 5 boiler was pre-treated by, in order, hot-side electrostatic precipitation (particulate removal), selective catalytic reduction $\left(\mathrm{NO}_{\mathrm{x}}\right.$ removal), and flue gas desulfurization $\left(\mathrm{SO}_{2}\right.$ removal) before passing into the PC4's caustic scrubber and then into the PCMS. These pre-treatments removed most of the common minor contaminants: the $\mathrm{SO}_{2}$ level was expected to be no more than $1 \mathrm{vppm}$ 
and NOx was expected to be at trace levels, leaving $\mathrm{CO}_{2}, \mathrm{O}_{2}, \mathrm{H}_{2} \mathrm{O}$ and inerts $\left(\mathrm{N}_{2}\right.$ and $\mathrm{Ar}$ ) as the only components of interest in the flue gas from an analytical standpoint. The flue gas is introduced to the PCMS at ambient temperature, close to atmospheric pressure, and is always fully saturated with water. Accordingly, the PCMS was designed to draw the flue gas using a pump, partially dehumidify it, and then send a portion of this gas into the membrane feed side. Figure 1 shows the flow diagram of the PCMS and Figure 2 shows the PCMS as installed at the NCCC. Reducing the feed gas dew point helps to avoid water condensation in the system without heating it, preventing damage to our sensitive electronic flow components. The sweep gas chosen was argon, based on both cost consideration and the fact that quantifying argon permeance is not generally important in assessing a membrane's performance. Both permeate and retentate (i.e. residual gas) streams are alternately sampled using a gas chromatograph equipped with a thermal conductivity detector (TCD) - further details on the GC are given in section 3.2.

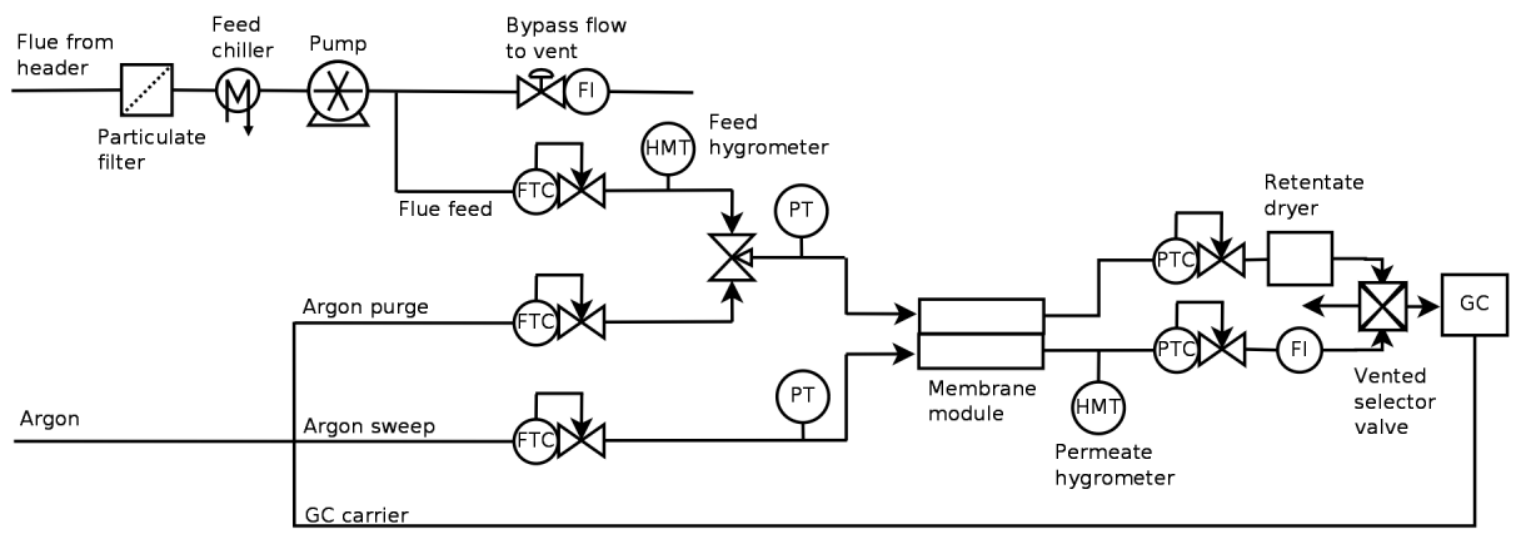

Figure 1. Simplified flow diagram of the PCMS. Module flow configuration is shown as co-current only to simplify the illustration. 


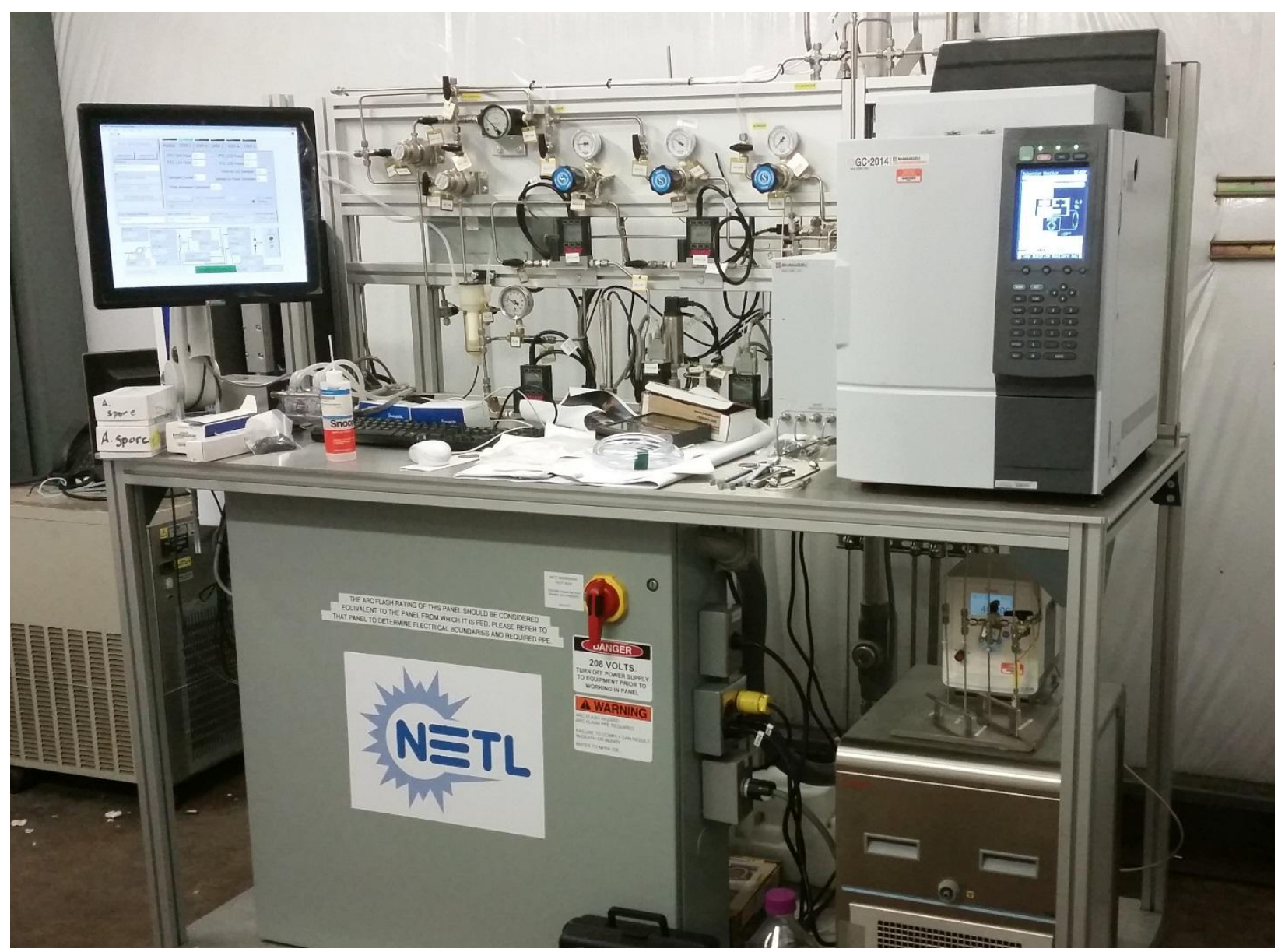

Figure 2. Picture of the PCMS, as installed at the NCCC-PC4 facility.

Based on a previous analysis, it was not practical to establish more than 2 bar of effective pressure differential between the upstream and downstream sides of a membrane intended for direct flue gas treatment [1]. Our flue gas pump is thus sized to pressurize the flue gas to no more than 2.5 bar gauge; our pressure controllers (from Alicat Scientific - Tucson, AZ) further limit the flue gas and sweep gas pressures to no more than 2 bar absolute. Also, because we planned to start with laboratory scale membranes, the Alicat mass flow controllers were ranged to flow only up to 50 $\mathrm{cm}^{3} /$ min of both flue and sweep gases for increased measurement accuracy. However, later in this report, we will show that the flue gas side mass flow controller was undersized and must be upgraded. In practice, the PCMS feed pump can supply more than $2 \mathrm{~L} / \mathrm{min}$ of flue gas, so the PCMS is amenable to further flowrate upgrades with minimal modifications.

The pressure and flow controllers installed at the PCMS have corrosion-resistant wetted materials for long operation life under flowing flue gas, but they are not designed to operate with condensed water in the line, and so a chiller was installed upstream of the pump to partially dehumidify the 
flue gas feed. The installed chiller is a Baldwin eCool e5800XP thermoelectric cooler (from PermaPure LLC, Lakewood, NJ), set at $4^{\circ} \mathrm{C}$, with capacity to cool up to $10 \mathrm{~L} / \mathrm{min}$ using two active impingers.

The gas chromatograph cannot measure the water content of the sampled streams; in fact, the separating columns are internally protected from water intrusion by using a retention column and a carrier gas flow path that backflushes this column after injection. Therefore, the PCMS measures the dew point of both the feed and permeate streams to assess water content and thus permeance using a pair of in-line probe hygrometers (HMT338 from Vaisala - Vantaa, FIN). The locations of these hygrometers are shown in Figure 1. The hygrometers were set to output dew point data into the data acquisition system, which can be converted to $\mathrm{H}_{2} \mathrm{O}$ partial pressure by using the Antoine equation:

$$
\log p_{H_{2} O}=A-\frac{B}{T_{d}+C}
$$

where $T_{d}$ is the dew point in K. Per recommendation of the NIST Chemistry Webbook, we used coefficients that are valid for the low dew points seen in these experiments: $A=4.6543, B=$ 1435.264, and $\mathrm{C}=-64.848[14]$.

Two types of membranes have been successfully tested with the PCMS: flat, free-standing polymer films and single strand hollow fiber membranes. The films were sealed using a custom cell made from off the shelf CF flanges, the same design as used previously [15] but using 2-1/8" (DN25) CF flange-to-1/8" female NPT fitting adapters instead (obtained from MDC Vacuum - Hayward, CA). The membrane to be tested is sealed within this cell supported on a porous metal disk and sealed to the upstream face of the cell using a Viton® O-ring. The upstream face was swept using the feed gas while the downstream face was swept using argon, through dip tubes to deliver the streams as close as possible to the membrane face, both with sufficient flowrate to ensure good gas mixing across the membrane face [8]. The gases on both sides of the membrane leave the cell via the tubing annuli. This particular cell size was chosen because a $25 \mathrm{~mm}$ diameter porous sintered 2 micron mesh stainless steel disk (1.6 mm thick), which can be readily obtained from various sources, will fit exactly within the DN25 copper gasket. Using this metal disk as membrane support minimizes the dead volume in the membrane cell, making the gas sweep across the downstream face of the membrane efficient even at relatively low flowrates. The Viton ${ }^{\circledR}$ 0-ring inner diameter on the upstream face of the membrane defines the permeation area. We used fractional 1/16" (1.6 mm) thick O-rings between size -014 and -018, corresponding to inner diameter of $12.7 \mathrm{~mm}$ to $19.0 \mathrm{~mm}$, 
i.e. $121 \mathrm{~mm}^{2}$ to $285 \mathrm{~mm}^{2}$ membrane area. Figure 3 shows the schematic and picture of the CF flange cell described in this paragraph.
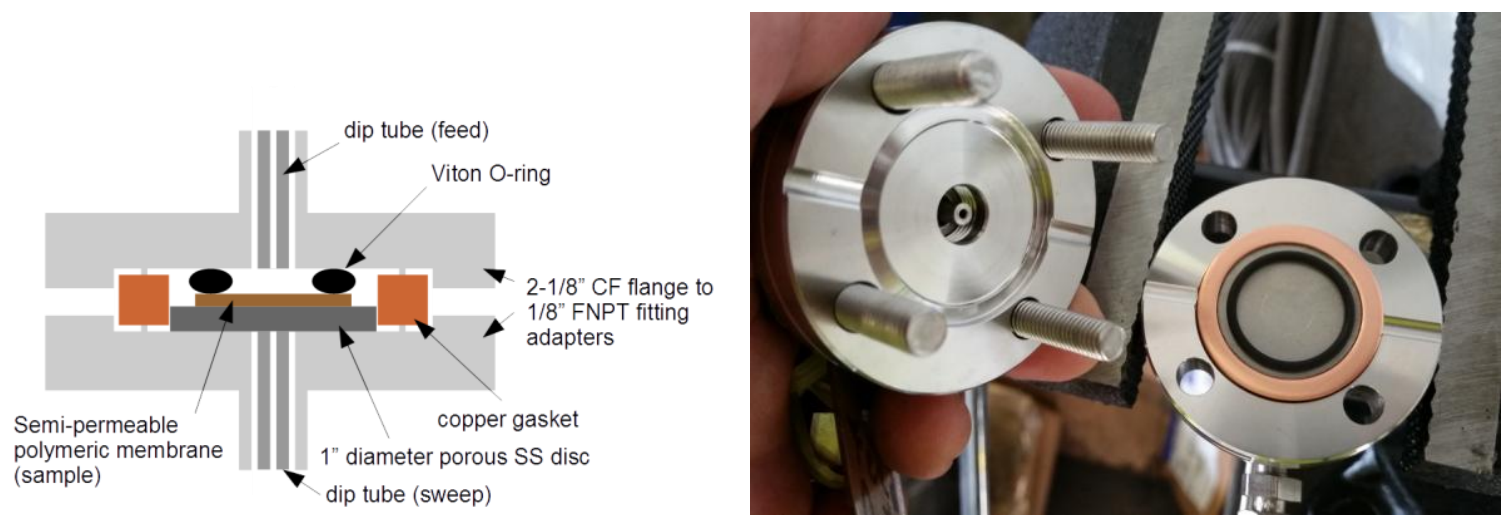

Figure 3. a) Schematic and b) picture of the CF flange flat sheet membrane cell assembly

Hollow fiber membranes were sealed into a cell made from a pair of stainless steel tee fittings in the same manner as reported in our previous work [5]. Briefly, a cell was constructed by connecting two run ends of the 1/4" ( $6 \mathrm{~mm}$ ) tees using a straight stainless steel tubing section. A single strand of hollow fiber was threaded through this straight section and is sealed on both ends of the tee using an epoxy adhesive. After curing the adhesive, the excess fiber was snapped off. The epoxy adhesive thus forms plugs on both ends of the cell, isolating the bore from the shell side of the membrane. Our effective membrane length is typically around $10 \mathrm{~cm}$ long. While the gas can be fed from either the bore or shell side, for the experiments we performed here we opted to flow the feed gas through the bore side. A picture for a hollow fiber membrane assembly we prepared is shown in Figure 4a. For comparison, we show the assembly for the CF flange cell in Figure 4b. Both assemblies can be readily installed to the PCMS using the fittings shown on the top of the figures: the feed gas flows from the rightmost outer tubing and exits as the retentate stream from the leftmost outer tubing, while the sweep gas enters the assembly from the left inner tubing and exits as the permeate stream from the right inner tubing. The membrane cells are maintained at the set temperature using a water bath circulator (cf. Fig 2): the high tubing surface area to volume ratio coupled with low flowrate (e.g. $10 \mathrm{~cm}^{3} / \mathrm{min}$ ) give the gas enough time to equilibrate to the desired membrane temperature even with the membrane assemblies having a relatively short immersed tubing length. The membrane temperature is dictated by the choice of the bath circulator and the heat transfer fluid - our choice of water means the PCMS is capable of testing between 5 to $80^{\circ} \mathrm{C}$, covering a good range of commonly cited flue gas separation process temperatures. 


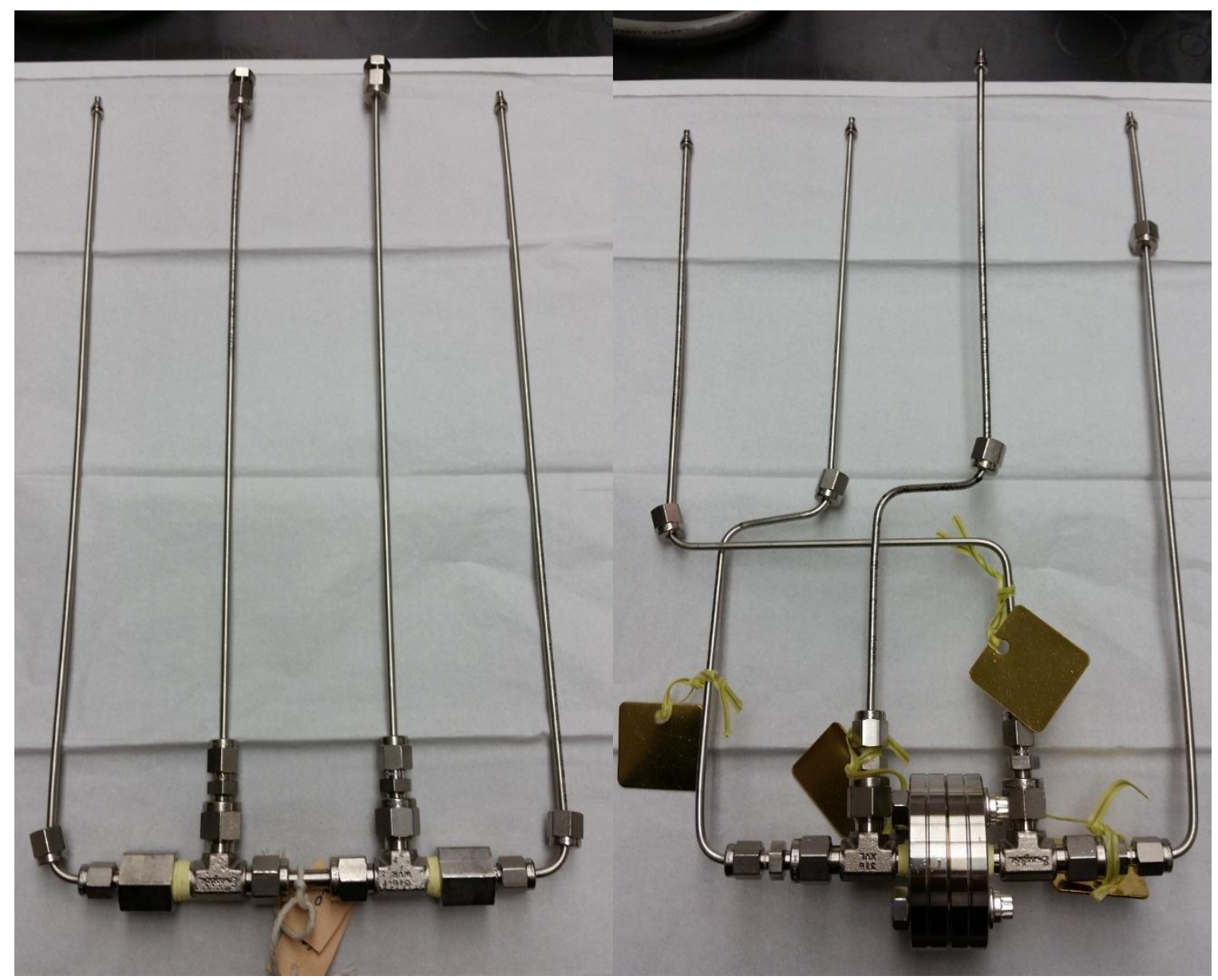

Figure 4. a) Hollow fiber and b) flat sheet membrane assemblies for the PCMS

\subsection{Gas composition analysis}

Accurate and reliable composition analysis of the permeate stream is the key requirement for any constant pressure mixed gas permeation system. We adopted the most common method for composition analysis for these system: gas chromatography using gas injection valves [8]. Our GC is a Shimadzu (Kyoto, JPN) GC-2014 set up by the manufacturer for fixed gas analysis using one thermal conductivity detector (TCD) with argon as the carrier gas. The columns were designed to separate the major flue gas components (i.e. nitrogen, oxygen, carbon dioxide) using a combination of polar and molecular sieve columns and reject water vapor using a backflush column. All target components elute within 10 minutes, which is much shorter than a typical sampling interval set up for long-term testing.

The GC was intended to sample both the retentate and the permeate streams - a pneumatically actuated, vented stream selector valve (Swagelok) upstream of the GC inlet allows the software to 
control the stream being sampled using a five-port two-position solenoid valve (SMC Corporation, Tokyo, JPN). Due to the low stage cut, the retentate stream is expected to have compositions very close to the feed stream (i.e. a few percent for $\mathrm{O}_{2}$ and $\mathrm{CO}_{2}$, around $80 \%$ for $\mathrm{N}_{2}$ ) whereas the permeate stream is expected to have concentrations in the hundreds to thousands parts per million. The disparate scale between the two streams necessitates the GC to use two separate calibration curves. The GC was calibrated by flowing directly into the GC inlet port several pre-mixed calibration standard gases (Airgas Specialty Gases, Durham, NC). For the retentate calibration, we ordered a $12 \% \mathrm{CO}_{2}, 4 \% \mathrm{O}_{2}$, balance $\mathrm{N}_{2}$ cylinder. For the permeate calibration, we used two gas cylinders: one containing $200 \mathrm{ppm}$ of $\mathrm{CO}_{2}$ and $\mathrm{N}_{2}$ in argon, and one containing $1000 \mathrm{ppm}$ of $\mathrm{CO}_{2}$ and $\mathrm{N}_{2}$ in argon. The lack of $\mathrm{O}_{2}$ in the permeate calibration standards was an oversight we corrected by using the $\mathrm{O}_{2}$ calibration curve obtained on the retentate side for all results reported in this study. For all calibration gases, we recorded six samples each and averaged the results to generate linear calibration curves for the individual components.

In addition to the backflush loop, we took an additional step to dry the retentate stream by using a PermaPure MD-050 series gas sample dryer. This is essentially a single strand Nafion® tubing membrane module where the retentate stream is fed through the bore side and dehumidified by sweeping house nitrogen countercurrently at around $1 \mathrm{~L} / \mathrm{min}$ and atmospheric pressure on the shell side [13]. Due to the relatively short dryer module length $(30 \mathrm{~cm})$ and the fact that the retentate contains about $80 \%$ nitrogen, we determined that the dryer will not significantly change the retentate composition on a dry basis [13]. However, the permeate stream is mostly argon with the other components present at concentrations potentially at low hundreds parts per million, including water. Therefore, we chose to feed the permeate stream directly into the GC without going through a PermaPure dryer.

\subsection{Computer hardware and software}

The PCMS was designed to perform a completely automated long-term experiment which does not require operator interaction after the initial setup. This was made possible by using state of the art data acquisition (DAQ) and control modules coupled with a rugged computer system. The PCMS is placed in a shed which protects it from the elements but otherwise does not have temperature control, and the electronic components were chosen based on their ability to operate at temperatures between $-10^{\circ} \mathrm{C}$ to $45^{\circ} \mathrm{C}$, which precludes using a regular desktop computer. The heart of the PCMS is a National Instruments (NI; Austin, TX) cDAQ-9132 CompactDAQ, a rugged computer running Microsoft Windows 7 Embedded and having four available slots to install input/output 
modules. To run the PCMS, we installed the following four modules: NI 9264 16-channel analog voltage output, NI 9207 8/8-channel analog voltage/current input, NI 9211 4-channel thermocouple input, and NI 9375 16/16-channel digital input/output. The CompactDAQ is mounted inside an electrical panel and interfaces with the operator using a monitor, keyboard and mouse (see Fig. 2).

The control software was written using NI LabVIEW 2013. The user interface of this software is shown in Figure 5. The software was designed to allow the user to pre-specify process parameters (flow rate, pressure), the number and frequency of sampling, and the initial purge time using argon if desired. GC sampling and analysis was set up using Shimadzu GCSolution software, running parallel with the PCMS control software - however, the timing for GC sampling is controlled by the PCMS software via the digital output module to ensure analysis synchronization. Up to five different sets of process parameters can be specified to run in a sequence. Once this testing sequence is started, user interaction is no longer necessary until completion. In a typical testing sequence, the PCMS will purge both sides of the membrane using argon for a set amount of time, before moving on to flow flue gas on the feed side and argon on the sweep side according to the process parameters for a pre-specified number of cycles.

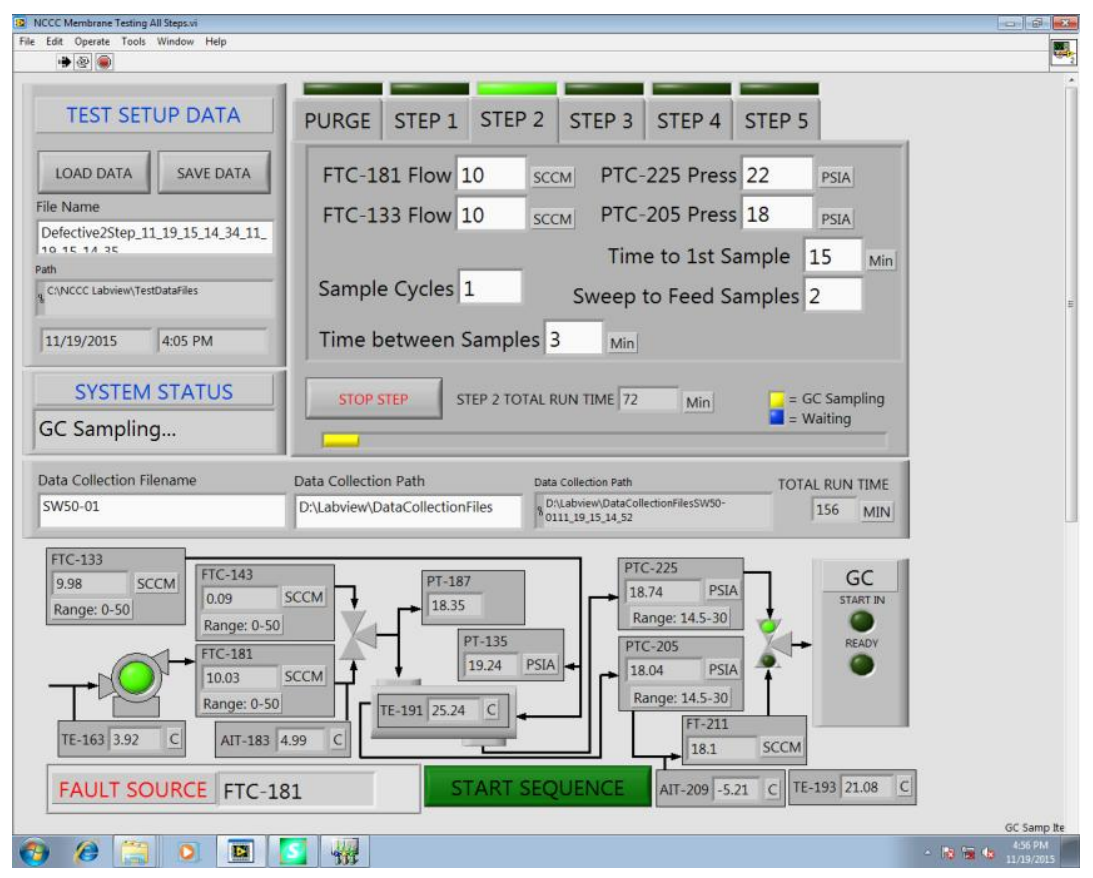

Figure 5. User interface of the PCMS control software 


\subsection{Operation notes and membranes tested}

The PCMS was first constructed and tested at NETL in Pittsburgh, PA before being shipped to NCCC in Wilsonville, AL. Installation and GC calibration were performed in early December 2015 followed by a week of testing several membranes that had been prepared in advance. Prior to shipment, all membranes were tested using standard mixed gas permeation systems at NETL for quality control and data comparison using a premixed feed gas $\left(20 \% \mathrm{CO}_{2}, 20 \% \mathrm{~N}_{2}\right.$, balance argon). In between the PCMS installation and the end of the testing time window, we tested seven membranes for 15 to 22.5 hours each.

All membranes were tested using a standard set of process parameters. The membrane was immersed in a recirculating bath filled with water set at $40^{\circ} \mathrm{C}$. Both the upstream and downstream sides of the membrane were set at 18.7 psia (1.3 bar) total pressure and $10 \mathrm{~cm}^{3} / \mathrm{min}$ flowrate. The separation driving force, therefore, is purely the partial pressure differences due to the different stream compositions. Table 1 summarizes our typical operating parameters.

Table 1. Operation parameters for membrane testing during our December 2015 testing period (cf. Figure 5)

\begin{tabular}{|c|c|}
\hline Membrane temperature & $40^{\circ} \mathrm{C}$ \\
\hline Initial argon purge time & 45 minutes \\
\hline Time to first sample & 30 minutes \\
\hline Sampling frequency & 30 minutes \\
\hline Sampling pattern & 4 permeate to 1 retentate \\
\hline Feed pressure & 18.7 psia (1.27 bar) \\
\hline Feed flowrate & $10 \mathrm{~cm}^{3} / \mathrm{min}$ \\
\hline Sweep pressure & 18.7 psia (1.27 bar) \\
\hline Sweep flowrate & $10 \mathrm{~cm}^{3} / \mathrm{min}$ \\
\hline
\end{tabular}

Our chosen standard membrane is polydimethylsiloxane (PDMS), obtained commercially as high purity high temperature silicone rubber sheets with a nominal thickness of $127 \mu \mathrm{m}$ from McMasterCarr. Gas permeation properties of PDMS are well-characterized in the literature [10,16,17], and the platinum-cured PDMS sheets obtained from this source exhibited gas permeability in line with these previous works. In addition to PDMS sheets, we also prepared several film coupons of poly(bis-trifluoroethoxyphosphazene) (TFE-PPZ), supplied to us by our collaborators in powder 
form and then solvent-cast from tetrahydrofuran (THF) solutions in our laboratory. This polymer has been previously characterized in multiple studies $[18,19]$ and has the right gas permeability to achieve permeate concentrations close to the GC detection limit as a free-standing film. The chemical structure for both PDMS and TFE-PPZ are given in Figure 6. Prior to being shipped to NCCC, the actual thicknesses of all films were determined at NETL using a Mitutoyo (Kawasaki, JPN) Litematic VL-50-B low force micrometer. Finally, to demonstrate the PCMS's ability to test thin film composite hollow fibers, we prepared and tested four hollow fiber samples. First, the support hollow fibers were made from Torlon ${ }^{\circledR}$ in a manner described in our previous work [20]: we chose the dope solution composition that gave the most surface porosity to minimize support fiber contribution to gas transport. These fibers were then dip-coated with TFE-PPZ based solutions in THF by hand, which produced a selective layer thickness on the order of several microns upon solvent removal. Our goal was to ensure a defect-free TFE-PPZ coating on the fibers, not to optimize for coating thickness, recognizing that TFE-PPZ by itself has too low $\mathrm{CO}_{2} / \mathrm{N}_{2}$ selectivity to be commercially interesting but instead serves as a springboard to further develop this class of materials. Two of the fibers were coated using a TFE-PPZ+THF solution, while the other two were coated with a TFE-PPZ+THF solution that also contained dispersed SIFSIX-Cu-2i [21], a metalorganic framework material that was previously found to be compatible with TFE-PPZ, creating a mixed matrix membrane coating on these Torlon® fibers [3].

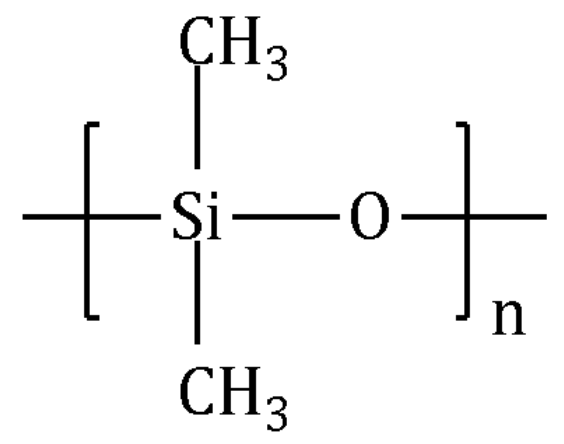

Figure 6. Chemical structures of

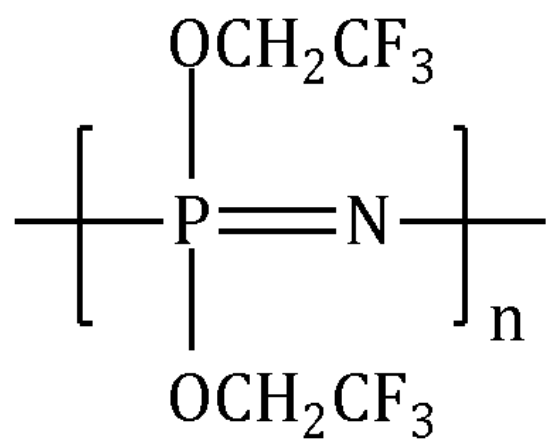

poly(dimethylsiloxane)

(PDMS) and poly(bistrifluoroethoxyphosphazene) (TFE-PPZ) 


\section{Results and Discussion}

\subsection{Feed characteristics}

In laboratory scale testing and in process modeling, a fixed flue gas composition is often assumed for simplicity. For instance, Merkel et al. initially modeled the performance of Polaris ${ }^{\mathrm{TM}}$ membranes based on an $11.6 \% \mathrm{CO}_{2}$ (wet basis) concentration in flue gas [22]. Testing at NCCC revealed that in reality, the feed composition can change significantly due to the changing operating conditions of the Gaston Unit 5, e.g. due to load demand or unscheduled downtime. White et al.'s study at NCCC over three test campaigns showed that while the average $\mathrm{CO}_{2}$ composition in their feed was $12 \%$ (dry basis), there were instances where the feed composition dropped to $11.0 \%$ [1]. Therefore, to quantify gas permeance accurately, the feed stream composition was also analyzed periodically.

The NCCC maintained a detailed assessment of the PC4 flue gas composition; however, we also performed composition validation both as a check for our instrument's reliability and to account for possible process disruptions that affect the flue gas characteristics close to the PCMS. Following the design of our previous mixed-gas constant pressure gas transport performance systems, we opted to analyze the retentate stream in lieu of the feed stream using the GC. Furthermore, since we have only one TCD channel in our GC, the stream selector valve upstream of the GC inlet switches between the permeate and retentate streams in a pre-specified pattern (see Figures 1 and 5). Our sampling pattern of four permeate plus one retentate with 30 minutes frequency (see Table 1) means the retentate stream was sampled every 2.5 hours, with the permeance data for the first four injections calculated based on the retentate gas composition determined by the fifth injection. The feed composition was then estimated by a mass balance calculation between the retentate and permeate compositions, and compared to the NCCC data. Taken together, the feed stream composition data over the period of our short term testing, as shown in Figure 7a, shows that the flue gas fed to the PCMS on December 2015 had somewhat lower $\mathrm{CO}_{2}$ concentration than the values reported by White et al. [1]: varying between $9.8 \%$ to $11.5 \%$ (dry basis), with a typical value of 10.5\%. $\mathrm{O}_{2}$ concentration varied from $7.9 \%$ to $9.7 \%$ with a typical concentration of $9.0 \%$. $\mathrm{N}_{2}$ concentration was measured by the PCMS GC without corroborating data from NCCC: we found $\mathrm{N}_{2}$ concentration varied from $80 \%$ to $82 \%$. In general, our calculated feed composition values agreed well with NCCC data. While we perform an additional drying step using the PermaPure Nafion fiber, the permeation rates of non-water vapor components were not significant enough to influence the dry basis retentate composition. 

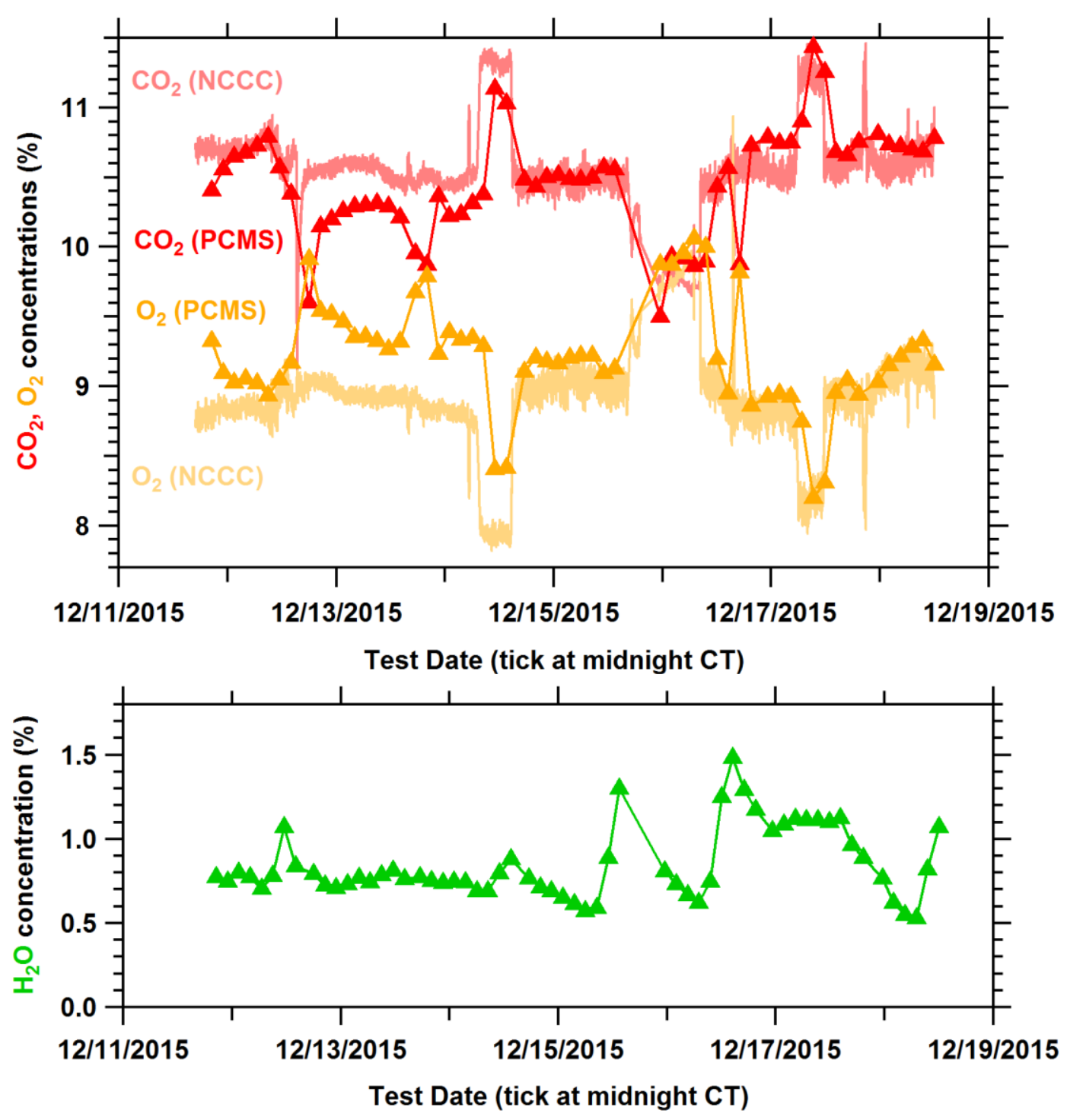

Figure 7. a) The dry basis $\mathrm{CO}_{2}$ and $\mathrm{O}_{2}$ composition in the feed stream, and b) the water vapor content of the feed stream, over the entire short term testing period in December 2015. The $\mathrm{CO}_{2}$ and $\mathrm{O}_{2}$ compositions analyzed by the NCCC are given as the lighter shaded lines on the background. CT stands for US Central Standard Time (UTC-6).

The water vapor content in the feed appears to reflect variations in the ambient temperature. It was always less than saturated because we removed water from the flue gas using the feed chiller to prevent condensation in the PCMS (cf. Figure 1). This feed contained $0.5 \%$ to $1.5 \% \mathrm{H}_{2} \mathrm{O}$, which translated to $15 \%$ to $25 \% \mathrm{RH}$ when fed to a membrane held at $40^{\circ} \mathrm{C}$. The variation in water vapor content during the testing period is shown in Figure $7 \mathrm{~b}$. 
The gaseous minor contaminants of interest in flue gas are sulfur oxides $\left(\mathrm{SO}_{\mathrm{x}}\right)$ and nitrogen oxides $\left(\mathrm{NO}_{\mathrm{x}}\right)$. These components were analyzed at $\mathrm{NCCC}$ as $\mathrm{SO}_{2}$ and $\mathrm{NO}_{2}$, respectively. The Gaston plant has removed most sulfur and nitrogen oxides from their Unit 5 emission to meet regulations, leaving only trace amounts in the flue gas supplied to the PC4 facility. Over the course of the testing week, the NCCC data revealed typical $\mathrm{SO}_{2}$ concentration of $1.2 \mathrm{ppm}$ and $\mathrm{NO}_{2}$ concentration of $10 \mathrm{ppm}$, with spikes no higher than $2.5 \mathrm{ppm}$ and $20 \mathrm{ppm}$, respectively. No sulfur or nitrogen oxides could be detected by our GC.

\subsection{Short term membrane testing results}

The December 2015 PCMS operation was our first attempt to quantify the water vapor permeability of a membrane using a constant pressure mixed gas membrane testing system. As mentioned in section 2, water vapor is the most permeable component in a flue gas stream and it is present at low concentrations (cf. Figure 7b); consequently, water vapor transport is often mass transfer limited due to concentration polarization $[12,23,24]$. To minimize concentration polarization, previous studies advocated using sufficient feed flow rate in a generic cell to ensure thorough mixing [23] and in the case of a flat sheet cell, enhanced mixing particularly on the feed side by using stainless steel wool packing [24]. The low velocity of our chosen $10 \mathrm{~cm}^{3} / \mathrm{min}$ feed side flow and lack of enhanced mixing on the feed side of the flat sheet cell suggest that water vapor transport in our membranes was severely mass transfer limited. Consequently, in the subsequent discussions, we will present the apparent water vapor permeance calculated from the hygrometer data using equation 3 with the caveat that it is underestimating the true water vapor permeance of the membrane.

Following the initial PCMS installation and calibration, we tested the PDMS flat sheet membrane using the process parameters given in Table 1 for 20 hours. The results are shown in Figure 8a. After the first hour, we measured a steady gas permeability: around 3300 barrer for $\mathrm{CO}_{2}, 400$ barrer for $\mathrm{N}_{2}$, and 760 barrer for $\mathrm{O}_{2}$. These values were virtually identical to the results we obtained in our other mixed gas permeation testing system at NETL (3400 barrer $\mathrm{CO}_{2}$ and 420 barrer $\mathrm{N}_{2}$ at $40^{\circ} \mathrm{C}$ ) and in excellent agreement particularly with results reported by Merkel et al. $[10,16]$. Table 2 shows a summary of gas permeability results from the literature and from our laboratory to allow better comparison with the data we obtained from the PCMS. Scholes et al. reported only very slight lowering of $\mathrm{CO}_{2}$ permeability for a PDMS composite membrane in a wet flue gas compared to dry [25], and we likewise did not see a significant drop in $\mathrm{CO}_{2}$ permeability in our partially dehydrated flue gas test. Finally, the apparent water vapor permeability we saw over the period of 20 hours 
varied from 16,000 to 20,000 barrer. The large variation, plus the fact that a number as high as 40,000 barrer has been reported in the literature [23], further confirms that the $10 \mathrm{~cm}^{3} / \mathrm{min}$ feed flowrate we chose was not enough to prevent concentration polarization, and thus not provide accurate value for the true water vapor permeability. 
Table 2. Select $\mathrm{CO}_{2}$ and $\mathrm{N}_{2}$ gas permeability or permeance results from the literature and internal tests for comparison with the PCMS results

\begin{tabular}{|c|c|c|c|c|c|c|}
\hline Membrane & $\begin{array}{l}\mathrm{CO}_{2} \text { permeability } \\
\text { or permeance }\end{array}$ & $\begin{array}{l}\mathrm{N}_{2} \text { permeability } \\
\text { or permeance }\end{array}$ & $\begin{array}{l}\mathrm{CO}_{2} / \mathrm{N}_{2} \\
\text { selectivity }\end{array}$ & Pressure and composition & Temp $\left({ }^{\circ} \mathrm{C}\right)$ & Source \\
\hline \multirow{4}{*}{ PDMS coupon } & 3800 barrer & 400 barrer & 9.5 & $<1$ bar, pure gases & 35 & [16] \\
\hline & 3200 barrer & 380 barrer & $\mathrm{N} / \mathrm{A}$ & $\begin{array}{l}2.4 \text { bar, simulated syngas mix } \\
\text { for } \mathrm{CO}_{2} \text {, pure for } \mathrm{N}_{2}\end{array}$ & 23 & {$[10]$} \\
\hline & 3400 barrer & 420 barrer & 8.1 & $\begin{array}{l}1.3 \text { bar, dry mixed }\left(20 \% \mathrm{CO}_{2},\right. \\
\left.20 \% \mathrm{~N}_{2} \text {, balance } \mathrm{Ar}\right)\end{array}$ & 40 & NETL \\
\hline & $3320 \pm 60$ barrer & $405 \pm 10$ barrer & 8.2 & 1.3 bar, flue gas (PCMS) & 40 & NCCC \\
\hline \multirow{4}{*}{$\begin{array}{l}\text { TFE-PPZ } \\
\text { coupon }\end{array}$} & 470 barrer & 35 barrer & 13.4 & 14.6 bar, pure gases & 35 & {$[18]$} \\
\hline & 580 barrer & 52 barrer & 11.2 & 2 bar, pure gases & 35 & [19] \\
\hline & 680 barrer & 79 barrer & 8.6 & $\begin{array}{l}1.3 \text { bar, dry mixed }\left(20 \% \mathrm{CO}_{2},\right. \\
\left.20 \% \mathrm{~N}_{2} \text {, balance } \mathrm{Ar}\right)\end{array}$ & 20 & NETL \\
\hline & $780 \pm 30$ barrer & $92 \pm 5$ barrer & 8.5 & 1.3 bar, flue gas (PCMS) & 40 & NCCC \\
\hline \multirow{2}{*}{$\begin{array}{c}\text { TFE-PPZ } \\
\text { hollow fiber }\end{array}$} & $55 \mathrm{GPU}$ & $4.3 \mathrm{GPU}$ & 13 & $\begin{array}{l}1.3 \text { bar, dry mixed }\left(20 \% \mathrm{CO}_{2},\right. \\
\left.20 \% \mathrm{~N}_{2} \text {, balance } \mathrm{Ar}\right)\end{array}$ & 20 & NETL \\
\hline & $50 \pm 2 \mathrm{GPU}$ & $4.8 \pm 0.1 \mathrm{GPU}$ & 10 & 1.3 bar, flue gas (PCMS) & 40 & NCCC \\
\hline \multirow{2}{*}{$\begin{array}{c}\text { TFE-PPZ } \\
\text { mixed matrix } \\
\text { hollow fiber }\end{array}$} & $34 \mathrm{GPU}$ & $2.2 \mathrm{GPU}$ & 15 & $\begin{array}{l}1.3 \text { bar, dry mixed }\left(20 \% \mathrm{CO}_{2},\right. \\
\left.20 \% \mathrm{~N}_{2} \text {, balance } \mathrm{Ar}\right)\end{array}$ & 20 & NETL \\
\hline & $19 \pm 1 \mathrm{GPU}$ & $1.9 \pm 0.1 \mathrm{GPU}$ & 10 & 1.3 bar, flue gas (PCMS) & 40 & NCCC \\
\hline
\end{tabular}

NETL designation indicates tests performed on dry pre-mixed gas permeation setup at NETL. NCCC designation indicates averaged steady state results on the PCMS data using flue gas with reduced dewpoint. Both sets are newly presented in this work. 

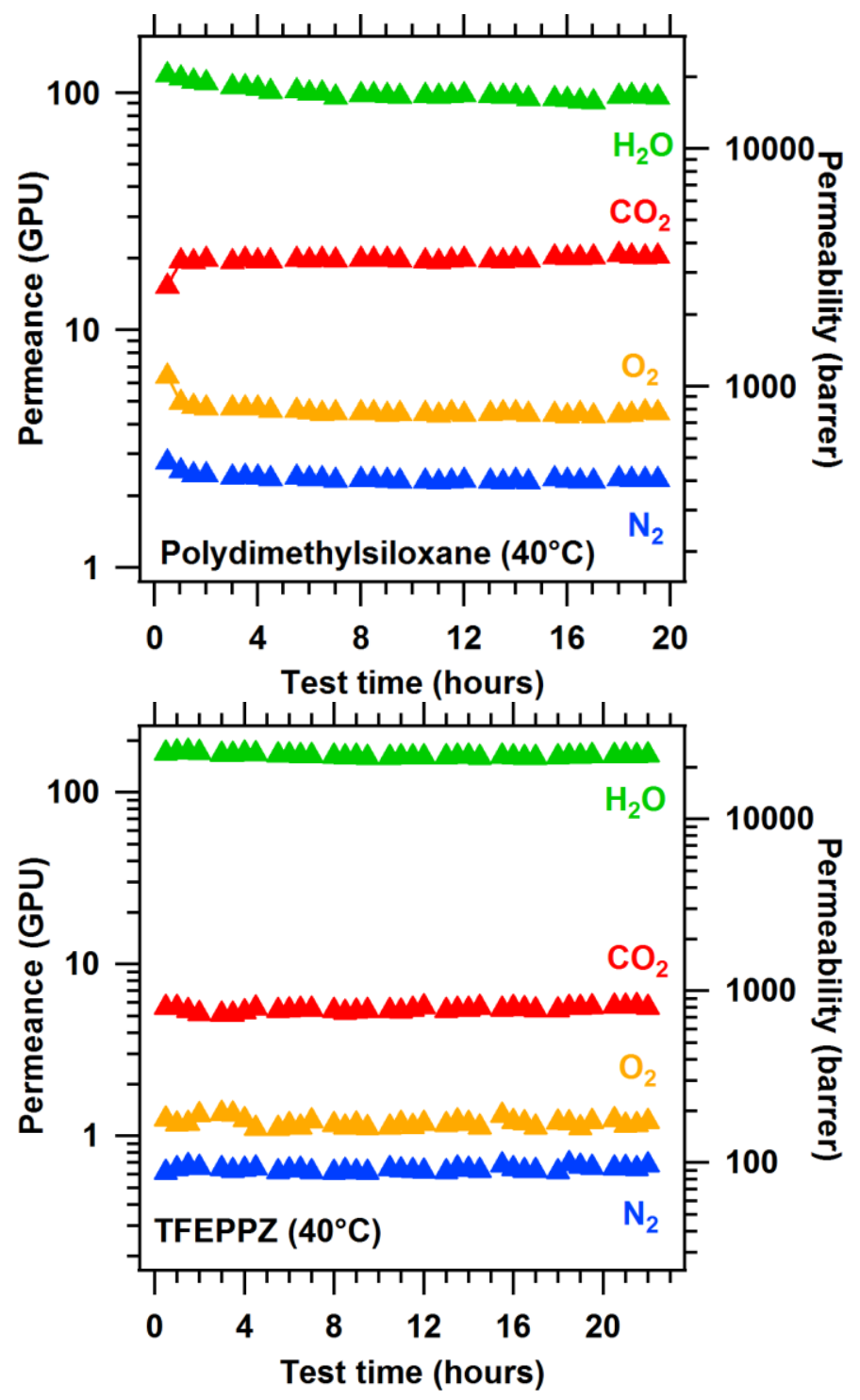

Figure 8. $\mathrm{CO}_{2}, \mathrm{~N}_{2}$ and $\mathrm{O}_{2}$ permeability of dense, flat sheets of a) PDMS and b) TFE-PPZ at $40^{\circ} \mathrm{C}$ and 1.3 bar upstream/downstream total pressures. Apparent $\mathrm{H}_{2} \mathrm{O}$ permeability, while also shown, does not reflect true water vapor permeability due to mass transfer limitations.

The gas permeability of the second flat sheet membrane tested, a coupon of TFE-PPZ, is shown in Figure $8 \mathrm{~b}$. The membrane area and thickness were chosen so that the permeate composition was close to the GC lower detection limit to test the measurement capability of the PCMS. Despite the resulting higher measurement uncertainty, ultimately we found the gas permeability values were stable over the 22 hour test. The average $\mathrm{CO}_{2}$ permeability, 780 barrer, was only slightly higher than the number we measured at NETL (680 barrer) but both values were much higher than the 
numbers reported elsewhere in the literature: 470 barrer [18] and 580 barrer [19] both taken at $35^{\circ} \mathrm{C}$ (Table 2). However, the film we tested was also three years old. Nagai et al. [18] have previously observed this literature discrepancy and speculated their sample might have been processed differently - due to the age of our film, we offer another possibility for the discrepancy, which is oxidation or hydrolysis. Our film's pure and mixed gas $\mathrm{CO}_{2} / \mathrm{N}_{2}$ selectivity was around 8.5 , lower than previously reported values of 13.4 [18] and 11.2 [19], so it is possible oxidation over time led to increased $\mathrm{CO}_{2}$ permeability and reduced $\mathrm{CO}_{2} / \mathrm{N}_{2}$ selectivity.

Following these flat sheet coupon tests, we also performed experiments on the four hollow fiber modules. The results from two of the thin film composite hollow fibers are given in Figure 9. Three of the four fibers exhibited stable $\mathrm{CO}_{2}, \mathrm{~N}_{2}$ and $\mathrm{O}_{2}$ permeance over periods of up to 22 hours - the other one, a TFE-PPZ coated fiber (Figure 9a), shows interesting behavior that we will discuss further below. The three aforementioned coated fibers, consisting of one TFE-PPZ and two TFEPPZ/SIFSIX coated fibers, displayed $\mathrm{CO}_{2} / \mathrm{N}_{2}$ selectivity around 10 to 11 (cf. Figure 9b). These are lower than the selectivity obtained during testing with dry mixed gas prior to being shipped to NCCC (cf. Table 2). The main reason for this selectivity reduction appears to have been the reduced $\mathrm{CO}_{2}$ permeance. For instance, the mixed matrix coated hollow fiber (Figure $9 \mathrm{~b}$ ) has steady state $\mathrm{CO}_{2}$ permeance of only 19 GPU under flue gas, vs. 34 GPU under dry mixed gases. Our sole outlier, shown in Figure 9a, might hint at a possible explanation for this discrepancy. This TFE-PPZ coated hollow fiber was loaded into the PCMS during a downtime and was exposed to the moist, stagnant environment inside the unit for a few hours. In a typical experiment, due to the dry argon sweep, the dewpoint on the permeate side is lower than the feed side - however, at the beginning of this experiment, the permeate side dewpoint was almost equal to the feed side dewpoint and continued to drop over time such that the calculated apparent water vapor permeance did not stabilize until about 15 hours into the experiment (cf. Figure 9a). This strongly implied that the downtime allowed the stagnant water vapor to condense on the membrane, and it was drying out as we flowed the drier gases through the module. Interestingly, while $\mathrm{N}_{2}$ and $\mathrm{O}_{2}$ permeance remained stable throughout the experiment even when the membrane was presumably wet, $\mathrm{CO}_{2}$ permeance started much lower in the first half hour (33 GPU) before rising and plateauing at around $50 \mathrm{GPU}$ starting on the sixth hour until the end of the experiment. This unexpected lowering of the $\mathrm{CO}_{2}$ permeance in the presence of water hints that $\mathrm{CO}_{2}$ transport might be strongly hindered by water in our TFE-PPZ hollow fiber. Scholes et al. has previously reported a modest lowering of both $\mathrm{CO}_{2}$ and $\mathrm{N}_{2}$ permeability of PDMS with increasing water content in a $\mathrm{CO}_{2} / \mathrm{N}_{2}$ mixed gas feed stream [25]; in contrast, the permeance decrease in our case was much more dramatic and exclusively applied to 
$\mathrm{CO}_{2}$. It appears the $\mathrm{CO}_{2}$ permeance of the TFE-PPZ is strongly affected by relative humidity. While even more dramatic losses in $\mathrm{CO}_{2}$ permeance observed on both mixed matrix hollow fiber coated membranes hint at performance loss for the SIFSIX-Cu-2i upon exposure to flue gas, at this point we have insufficient data to understand the exact mechanism. Confirmation of both phenomena require further parametric studies with longer exposure to flue gas and additional tests beyond the scope of this report.
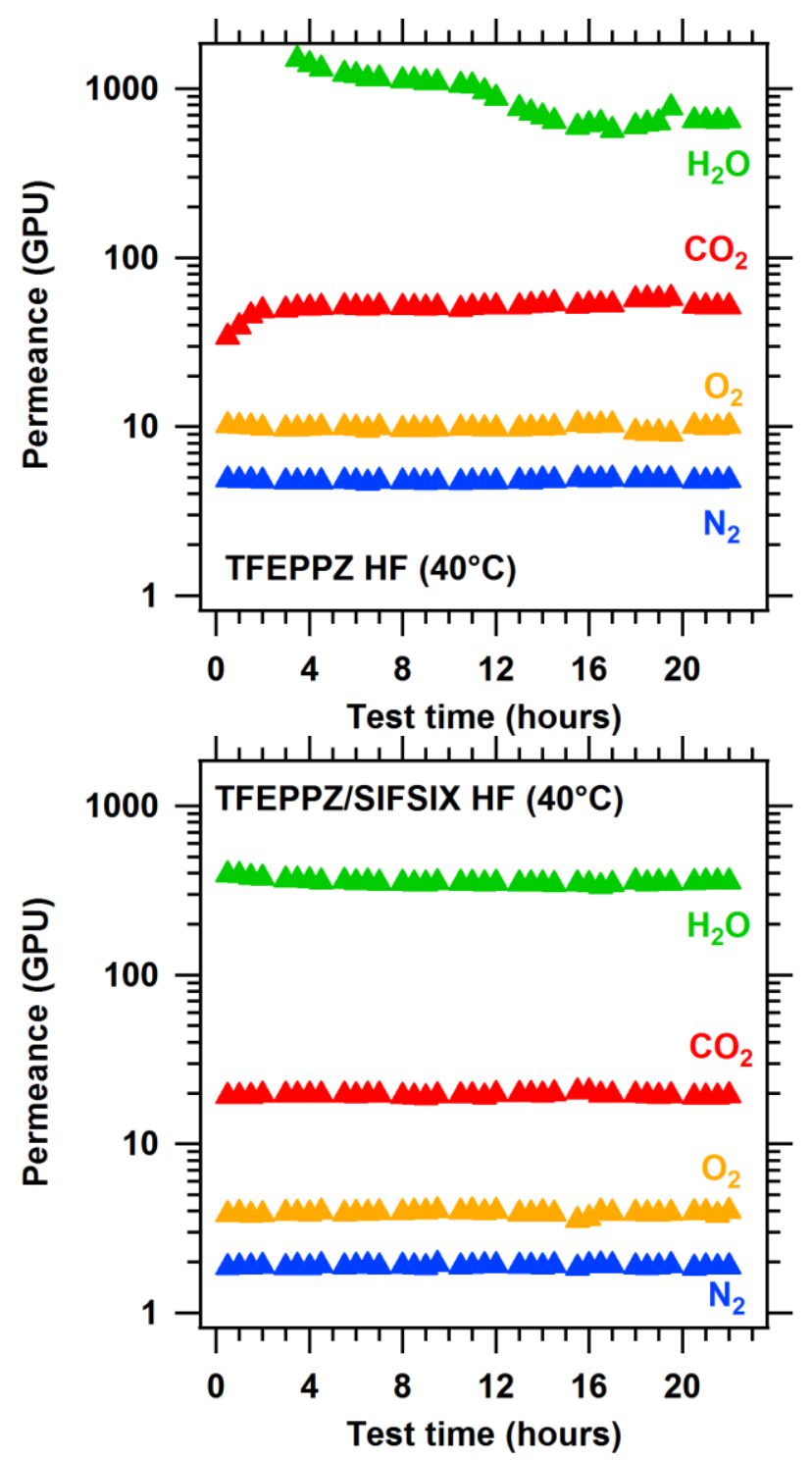

Figure 9. $\mathrm{CO}_{2}, \mathrm{~N}_{2}$ and $\mathrm{O}_{2}$ permeability of two porous Torlon® hollow fibers coated with a) TFE-PPZ and b) TFE-PPZ/SIFSIX-Cu-2i at $40^{\circ} \mathrm{C}$ and 1.3 bar upstream/downstream total pressures. Apparent $\mathrm{H}_{2} \mathrm{O}$ permeability, while also given, does not reflect true water vapor permeability due to mass transfer limitations. 
The final membrane tested by the PCMS during the December 2015 testing period was a mixed matrix flat sheet film consisting of two microporous polymers: PIM-1 as matrix and BILP-101 as filler. The testing results for this novel system have been previously reported [26].

\section{Conclusions}

In this study, we utilized the new flue gas membrane testing system installed at the National Carbon Capture Center to quantify the $\mathrm{CO}_{2}, \mathrm{~N}_{2}, \mathrm{O}_{2}$ and water vapor permeances of three different polymerbased films as well as four porous hollow fiber membranes coated with thin selective polymer or polymer/metal organic framework composite. The standard polydimethylsiloxane film displayed gas permeances within the expected ranges based on literature data for dry gas feeds. The measured permeances for the poly(bistriflouroethoxyphosphazene) [TFE-PPZ] film were low by design; thus, the assigned measurement uncertainty did not allow us to ascertain the flue gas effect on membrane performance. However, the four hollow fibers coated with TFE-PPZ based coatings did suggest that their $\mathrm{CO}_{2}$ permeances were lowered upon exposure to flue gas. While apparent water vapor permeances were quantified for all membranes, the operation parameters were not set to address concentration polarization and thus the numbers reported here underestimated the true water vapor permeances of the membranes.

\section{Future Outlook}

We are highly encouraged by the results obtained from the PCMS in the short time we have had the opportunity to operate it. The PCMS was built upon a well-known membrane measurement method that we have practiced for several years, making the PCMS a reliable, universal membrane performance testing skid that is in operation at one of the world's premier carbon capture research centers. The initial operations at the NCCC provided an invaluable learning experience in membrane testing using a humid flue gas. For instance, we did not initially expect concentration polarization to be a major issue in measuring water vapor permeance. We later confirmed that testing the PDMS coupon at a $50 \mathrm{~cm}^{3} / \mathrm{min}$ feed flow increased the apparent water vapor permeability to 25,000-28,000 barrer (from 16,000-20,000 barrer at $10 \mathrm{~cm}^{3} / \mathrm{min}$ ) with practically no change to the measured permeability for other gases. One change we performed after the initial test was to upgrade the feed mass flow controller to enable greater than $50 \mathrm{~cm}^{3} / \mathrm{min}$ flow so that the PCMS can be used to test membranes with higher permeances and/or larger surface area. The simple and modular PCMS design easily allowed such capacity expansion without fundamentally changing the skid operation. 
While the ability of the PCMS to conduct long-term experiments on high performance laboratoryscale membranes has yet to be demonstrated, there are no unsurmountable technical hurdles to do so successfully as long as periodic maintenance is performed particularly on the gas chromatograph. Our short-term testing revealed that to reduce the experiment's vulnerability to process disruptions and changing water content, membranes should be tested over the span of at least several days to better assess true membrane performance. We continue to work on improving the PCMS' ability to evaluate the long-term stability of our higher performance membranes for real flue gas separations.

\section{Acknowledgements and Disclaimer}

This technical effort was performed in support of the U.S. Department of Energy's National Energy Technology Laboratory's ongoing research on $\mathrm{CO}_{2}$ capture under the Carbon Capture field work proposal and RES contract DE-FE0004000. This research was supported in part by an appointment to the National Energy Technology Laboratory Research Participation Program, sponsored by the U.S. Department of Energy and administered by the Oak Ridge Institute for Science and Education.

Many people contributed to the overall effort for making the PCMS a success. We would like to specifically thank Jeffrey Hash for process flow design and PCMS layout, Ron Hirsh and Ray Rokicki for installing the PCMS flow components, Bill Walker for the PCMS instrumentation installation, Rocky Stoneking for the PCMS electrical installation and Rich Valdisera for coordinating the construction effort. We acknowledge the assistance of Shimadzu Corp., particularly through Heather Juzwa and Mark Waksmonski, for configuring the GC and for helping with the inevitable troubleshooting. We would like to thank Robert Lambrecht from Southern Company Services for his assistance in troubleshooting the PCMS GC on site and invaluable technical advice on gas composition measurement. Poly(bis-trifluoroethoxyphosphazene) was supplied to us by Prof. Harry Allcock's research group at the Pennsylvania State University, and SIFSIX-Cu-2i was synthesized at NETL by Anne Marti.

This project was funded by the Department of Energy, National Energy Technology Laboratory, an agency of the United States Government, through a support contract with AECOM. Neither the United States Government nor any agency thereof, nor any of their employees, nor AECOM, nor any of their employees, makes any warranty, expressed or implied, or assumes any legal liability or responsibility for the accuracy, completeness, or usefulness of any information, apparatus, product, or process disclosed, or represents that its use would not infringe privately owned rights. Reference 
herein to any specific commercial product, process, or service by trade name, trademark, manufacturer, or otherwise, does not necessarily constitute or imply its endorsement, recommendation, or favoring by the United States Government or any agency thereof. The views and opinions of authors expressed herein do not necessarily state or reflect those of the United States Government or any agency thereof.

\section{References}

[1] L.S. White, X. Wei, S. Pande, T. Wu, T.C. Merkel, Extended flue gas trials with a membranebased pilot plant at a one-ton-per-day carbon capture rate, J. Memb. Sci. 496 (2015) 48-57. doi:10.1016/j.memsci.2015.08.003.

[2] H. Lin, Z. He, Z. Sun, J. Vu, A. Ng, M. Mohammed, J. Kniep, T.C. Merkel, T. Wu, R.C. Lambrecht, $\mathrm{CO}_{2}$-selective membranes for hydrogen production and $\mathrm{CO}_{2}$ capture - Part I: Membrane development, J. Memb. Sci. 457 (2014) 149-161. doi:10.1016/j.memsci.2014.01.020.

[3] 2015 NETL $\mathrm{CO}_{2}$ Capture Technology Meeting, http://www.netl.doe.gov/events/conferenceproceedings/2015/2015-co2-capture-technology-meeting, http://www.netl.doe.gov/events/conference-proceedings/2015/2015-co2-capturetechnology-meeting.

[4] S.R. Venna, M. Lartey, T. Li, A. Spore, S. Kumar, H.B. Nulwala, D.R. Luebke, N.L. Rosi, E. Albenze, Fabrication of MMMs with improved gas separation properties using externallyfunctionalized MOF particles, J. Mater. Chem. A. 3 (2015) 5014-5022. doi:10.1039/C4TA05225K.

[5] S. Wickramanayake, D. Hopkinson, C. Myers, L. Sui, D. Luebke, Investigation of transport and mechanical properties of hollow fiber membranes containing ionic liquids for precombustion carbon dioxide capture, J. Memb. Sci. 439 (2013) 58-67. doi:10.1016/j.memsci.2013.03.039.

[6] C. Myers, H. Pennline, D. Luebke, J. Ilconich, J.K. Dixon, E.J. Maginn, J.F. Brennecke, High temperature separation of carbon dioxide/hydrogen mixtures using facilitated supported ionic liquid membranes, J. Memb. Sci. 322 (2008) 28-31. doi:10.1016/j.memsci.2008.04.062.

[7] W. Shi, C.R. Myers, D.R. Luebke, J.A. Steckel, D.C. Sorescu, Theoretical and experimental studies of $\mathrm{CO}_{2}$ and $\mathrm{H}_{2}$ separation using the 1-ethyl-3-methylimidazolium acetate ([emim] $]\left[\mathrm{CH}_{3} \mathrm{COO}\right]$ ) ionic liquid., J. Phys. Chem. B. 116 (2012) 283-95. doi:10.1021/jp205830d.

[8] H. Lin, B.D. Freeman, Permeation and Diffusion, in: H. Czichos, L.E. Smith, T. Saito (Eds.), Springer-Handb. Mater. Meas. Methods, Springer, Berlin, 2006: pp. 371-387.

[9] R. Swaidan, X. Ma, E. Litwiller, I. Pinnau, High pressure pure- and mixed-gas separation of $\mathrm{CO}_{2} / \mathrm{CH}_{4}$ by thermally-rearranged and carbon molecular sieve membranes derived from a polyimide of intrinsic microporosity, J. Memb. Sci. 447 (2013) 387-394. doi:10.1016/j.memsci.2013.07.057.

[10] T.C. Merkel, R.P. Gupta, B.S. Turk, B.D. Freeman, Mixed-gas permeation of syngas components in poly (dimethylsiloxane) and poly (1-trimethylsilyl-1-propyne) at elevated temperatures, J. Memb. Sci. 191 (2001) 85-94. doi:10.1016/S0376-7388(01)00452-5. 
[11] W.J. Koros, G.K. Fleming, Membrane-based gas separation, J. Memb. Sci. 83 (1993) 1-80. doi:10.1016/0376-7388(93)80013-N.

[12] K.L. Wang, S.H. McCray, D.D. Newbold, E.L. Cussler, Hollow fiber air drying, J. Memb. Sci. 72 (1992) 231-244. doi:10.1016/0376-7388(92)85051-J.

[13] X. Ye, M. Douglas LeVan, Water transport properties of Nafion membranes, J. Memb. Sci. 221 (2003) 147-161. doi:10.1016/S0376-7388(03)00255-2.

[14] D.R. Stull, Vapor Pressure of Pure Substances. Organic and Inorganic Compounds, Ind. Eng. Chem. 39 (1947) 517-540. doi:10.1021/ie50448a022.

[15] V.A. Kusuma, E.A. Roth, W.P. Clafshenkel, S.S. Klara, X. Zhou, S.R. Venna, E. Albenze, D.R. Luebke, M.S. Mauter, R.R. Koepsel, A.J. Russell, D. Hopkinson, H.B. Nulwala, Crosslinked poly(ethylene oxide) containing siloxanes fabricated through thiol-ene photochemistry, J. Polym. Sci. Part A Polym. Chem. 53 (2015) 1548-1557. doi:10.1002/pola.27594.

[16] T.C. Merkel, V.I. Bondar, K. Nagai, B.D. Freeman, I. Pinnau, Gas sorption, diffusion, and permeation in poly(dimethylsiloxane), J. Polym. Sci. Part B Polym. Phys. 38 (2000) 415-434. doi:10.1002/(SICI)1099-0488(20000201)38:3<415::AID-POLB8>3.0.CO;2-Z.

[17] S.A. Stern, V.M. Shah, B.J. Hardy, Structure-Permeability Relationships in Silicone Polymers, J. Polym. Sci. B Polym. Phys. 25 (1987) 1263-1298. doi:10.1002/polb.1987.090250607.

[18] K. Nagai, B.D. Freeman, A. Cannon, H.R. Allcock, Gas permeability of poly(bistrifluoroethoxyphosphazene) and blends with adamantane amino/trifluoroethoxy (50/50) polyphosphazene, J. Memb. Sci. 172 (2000) 167-176. doi:10.1016/S0376-7388(00)00333-1.

[19] H.R. Allcock, C.J. Nelson, W.D. Coggio, I. Manners, W.J. Koros, D.R.B. Walker, L.A. Pessan, Gas permeation and selectivity of poly(organophosphazene) membranes, Macromolecules. 26 (1993) 1493-1502. doi:10.1021/ma00059a003.

[20] S. Wickramanayake, D. Hopkinson, C. Myers, L. Hong, J. Feng, Y. Seol, D. Plasynski, M. Zeh, D. Luebke, Mechanically robust hollow fiber supported ionic liquid membranes for $\mathrm{CO}_{2}$ separation applications, J. Memb. Sci. 470 (2014) 52-59. doi:10.1016/j.memsci.2014.07.015.

[21] P. Nugent, Y. Belmabkhout, S.D. Burd, A.J. Cairns, R. Luebke, K. Forrest, T. Pham, S. Ma, B. Space, L. Wojtas, M. Eddaoudi, M.J. Zaworotko, Porous materials with optimal adsorption thermodynamics and kinetics for $\mathrm{CO}_{2}$ separation, Nature. 495 (2013) 80-84. doi:10.1038/nature11893.

[22] T.C. Merkel, H. Lin, X. Wei, R. Baker, Power plant post-combustion carbon dioxide capture: An opportunity for membranes, J. Memb. Sci. 359 (2010) 126-139. doi:10.1016/j.memsci.2009.10.041.

[23] S.J. Metz, W.J.C. Van De Ven, J. Potreck, M.H. V Mulder, M. Wessling, Transport of water vapor and inert gas mixtures through highly selective and highly permeable polymer membranes, J. Memb. Sci. 251 (2005) 29-41. doi:10.1016/j.memsci.2004.08.036.

[24] G.Q. Chen, C.A. Scholes, G.G. Qiao, S.E. Kentish, Water vapor permeation in polyimide membranes, J. Memb. Sci. 379 (2011) 479-487. doi:10.1016/j.memsci.2011.06.023.

[25] C.A. Scholes, G.W. Stevens, S.E. Kentish, The effect of hydrogen sulfide, carbon monoxide and water on the performance of a PDMS membrane in carbon dioxide/nitrogen separation, J. Memb. Sci. 350 (2010) 189-199. doi:10.1016/j.memsci.2009.12.027.

[26] A.K. Sekizkardes, V.A. Kusuma, G. Dahe, E.A. Roth, L.J. Hill, A. Marti, M. Macala, S.R. Venna, D. 
Hopkinson, Separation of carbon dioxide from flue gas by mixed matrix membranes using dual phase microporous polymeric constituents, Chem. Commun. 52 (2016) 11768-11771. doi:10.1039/C6CC04811K. 